\title{
A comprehensive evaluation of water uptake on atmospherically relevant mineral surfaces: DRIFT spectroscopy, thermogravimetric analysis and aerosol growth measurements
}

\author{
R. J. Gustafsson, A. Orlov, C. L. Badger, P. T. Griffiths, R. A. Cox, and R. M. Lambert \\ Chemistry Department, Cambridge University, Lensfield Road, Cambridge CB2 1EW, UK
}

Received: 4 August 2005 - Published in Atmos. Chem. Phys. Discuss.: 22 August 2005

Revised: 14 November 2005 - Accepted: 23 November 2005 - Published: 19 December 2005

\begin{abstract}
The hygroscopicity of mineral aerosol samples has been examined by three independent methods: diffuse reflectance infrared Fourier transform spectroscopy, thermogravimetric analysis and differential mobility analysis. All three methods allow an evaluation of the water coverage of two samples, $\mathrm{CaCO}_{3}$ and Arizona Test dust, as a function of relative humidity. For the first time, a correlation between absolute gravimetric measurements and the other two (indirect) methods has been established. Water uptake isotherms were reliably determined for both solids which at $298 \mathrm{~K}$ and $80 \%$ relative humidity exhibited similar coverages of $\sim 4$ monolayers. However, the behaviour at low relative humidity was markedly different in the two cases, with Arizona Test Dust showing a substantially higher affinity for water in the contact layer. This is understandable in terms of the chemical composition of these two materials. The mobility analysis results are in good accord with field observations and with our own spectroscopic and gravimetric measurements. These findings are of value for an understanding of atmospheric chemical processes.
\end{abstract}

\section{Introduction}

The physicochemical properties of aerosol particles affect the radiative balance and chemistry of the Earth's atmosphere. The hygroscopic properties of aerosol particles are important both to their direct and indirect effects on the Earth's radiation budget. Aerosols affect the radiative balance of the Earth by scattering and absorbing solar radiation (Kaufman et al., 2002). The single scattering albedo of a particle depends on its size and refractive index, both of which are strong functions of the aerosol water content.

Correspondence to: R. M. Lambert

(rml1@cam.ac.uk)
Cloud droplets form via the condensational growth of aerosol particles, and the hygroscopic properties of the aerosol surface control the rate of activation of aerosol particles to form cloud droplets. The optical properties and lifetime of the resulting cloud depend on the hygroscopicity of the initial aerosol on which the cloud droplets form (Charlson et al., 1992).

Aerosols also provide a sink for reactive gases as well as a substrate for chemical transformation (Ravishankara and Longfellow, 1999), and aerosol water content has been shown to affect the rate of uptake of soluble gases (Hallquist et al., 2003). Measurements of hygroscopic growth and associated water content are therefore necessary to understand the radiative and chemical effects of tropospheric aerosol species.

Mineral dust aerosol is an important component of the atmosphere, comprising the fine particles of crustal origin advected from arid regions and consisting primarily of silica and silicate minerals. It is estimated that between 1000 and $3000 \mathrm{Tg} / \mathrm{year}$ are emitted into the atmosphere, primarily in the Northern Hemisphere from the Sahara, the Arabian peninsula and central Asia (Tegen and Fung, 1994). The fine, sub- $10 \mu \mathrm{m}$ fraction has an atmospheric lifetime of several days and can be transported over thousands of kilometres (Savoie and Prospero, 1982). The short lifetime and uneven distribution of sources can lead to strong spatial and temporal variability in radiative forcing, particularly over the North Atlantic Ocean and South East Asia (Garrett et al., 2003). Mineral dust can also affect the atmospheric chemistry through removal of traces gases such as $\mathrm{SO}_{2}$ and $\mathrm{HNO}_{3}$ (Hanke et al., 2003) and it is known that mineral dust particles are frequently coated with sulphate and other electrolytes (Li-Jones and Prospero, 1998) as a result of atmospheric processing. The hygroscopic properties of aged aerosols are therefore expected to differ significantly from those of a freshly emitted aerosol, with important consequences for the radiative and chemical properties.

(C) 2005 Author(s). This work is licensed under a Creative Commons License. 
We report water uptake for two classes of aerosol: calcite, i.e. $\mathrm{CaCO}_{3}$, and Arizona Test Dust. Calcite is an important component of Saharan dust, comprising up to $30 \%$ of the aerosol mass (Loyepilot et al., 1986). The water content of calcite particles is important in the atmospheric oxidation of $\mathrm{SO}_{2}$ that proceeds via the formation of a calcium sulfate hemihydrate (Dentener et al., 1996).

In the work reported in this article, the water uptake was measured by two different techniques: diffuse reflectance Fourier transform spectroscopy (DRIFTS), and thermogravimetic analysis (TGA). Additionally, the size distribution of a laboratory-generated aerosol, and therefore approximate water content, was measured using a scanning electrical differential mobility analyser (DMA).

\section{Experimental methods}

\subsection{Sample preparation and characterization}

The samples analyzed were Arizona Test Dust (nominal 0$3 \mu \mathrm{m}$ fraction, Powder Technology Inc., Minnesota, USA) and calcite (Specialty Minerals Ltd, Birmingham, UK, nominal diameter $\sim 70 \mathrm{~nm}$ ). Prior to DRIFTS and TGA experiments the samples were conditioned for one hour at $120^{\circ} \mathrm{C}$ under helium to remove the majority of species adsorbed on the surface. Surface area analysis was performed using a Micromeritics Gemini BET analyser.

\subsection{Diffuse reflectance Fourier Transformed spectroscopy (DRIFTS)}

DRIFTS experiments were performed with a Perkin-Elmer GX2000 spectrometer equipped with a liquid nitrogen cooled MCT detector. The DRIFTS sample (Collector II, Thermo Spectra-Tech) was installed in a controlled atmosphere cell that also allowed control of the sample temperature. The detector and sample areas of the spectrometer were purged with $\mathrm{N}_{2}$ to reduce the contribution of atmospheric $\mathrm{CO}_{2}$ and $\mathrm{H}_{2} \mathrm{O}$. Accurate flows of humid gas were obtained using mass flow controllers (MKS) to pass a controlled proportion of the total gas through high purity deionized water. Relative humidity $(R H)$ was measured with a humidity probe (Vaisala Humitter) and difference spectra were acquired at $25^{\circ} \mathrm{C}$ with a resolution of $4 \mathrm{~cm}^{-1}$ (average of 100 scans). Background spectra of the conditioned sample were taken under a flow of helium at $25^{\circ} \mathrm{C}$.

\subsection{Thermogravimetric analysis (TGA)}

TGA experiments were performed using a Mettler-Toledo TGA/SDTA851e with an accuracy of $+/-1 \mu \mathrm{g}$. The balance and sample compartments were purged with nitrogen. The weight of the sample was measured continuously under isothermal conditions. The humidity of the purge gas was increased in steps, the balance output being allowed to stabilise between each step. The experiment was repeated without the sample present to correct for water adsorption to the sample holder and balance apparatus.

\subsection{Aerosol growth measurements}

Hygroscopic growth factors are derived from size distributions measured as a function of relative humidity $(R H)$ by calculating the ratio of mean particle diameter of an aerosol distribution at a given $R H$ to that of similar particles at a $R H$ below $30 \%$. Aerosols were generated using a slow-flow nebulizer system, based on the design of Lindqvist et al. (1982). The nebulizer holds a continuously stirred suspension of particles in distilled water, and a peristaltic pump generates a flow of approximately $2 \mathrm{ml} \mathrm{min}^{-1}$ through the hypodermic needle of the nebulizer system. At the exit of the needle, the flow of liquid meets a fast flow of $\mathrm{N}_{2}(0.5-1.5 \mathrm{slm})$, generating an aerosol with a number density of approximately $1 \times 10^{6}$ particles $\mathrm{cm}^{-3}$.

For certain measurements, the aerosol stream was dried to $<2 \% R H$ by passing the flow through a pair of diffusion driers, which contain a clear channel around which a silica gel/cobalt chloride drying agent is packed. The relative humidity of the aerosol stream was controlled by the addition of a flow of humidified nitrogen. With the driers in the flow stream, a final $R H$ of between 2 and $70 \%$ can be generated. When the driers are bypassed, a range of $30-82 \% R H$ is accessible. The aerosol stream was passed to a Pyrex conditioner and then to the DMA (Hauke, VIE-EMS-08). Size distributions are calculated by proprietary software that corrects for the effects of multiple charging, assuming spherical particle shape.

Aerosols were generated from suspensions in distilled water of calcite particles and Arizona Test Dust. The calcite particles were used as supplied, while the Arizona Test Dust sample was filtered using Fisherbrand QT 260 filter paper, and the filtrate used in the nebulizer - a procedure found to give the most stable operation. Filtration reduced the concentration of dust in the suspension from $20 \mathrm{mg} \mathrm{cm}^{-3}$ to $10.6 \mathrm{mg} \mathrm{cm}^{-3}$, a reduction of $47 \%$.

\section{Results}

\subsection{Water uptake on calcium carbonate}

Adsorption of water vapour onto the $\mathrm{CaCO}_{3}$ surface was measured at room temperature by means of DRIFTS: the integrated intensity of the O-H stretching region (ca. 3000$3700 \mathrm{~cm}^{-1}$, see inset Fig. 1) provides a measure of the amount of water on the surface (Saliba et al., 2001).

The peak in this region is a combination of vibrational modes: symmetric stretch at $3423 \mathrm{~cm}^{-1}$ and asymmetric stretch at $3253 \mathrm{~cm}^{-1}$. The absorbance of these modes is suitably strong to monitor water adsorption on the surfaces of the particles (Goodman et al., 2001). 


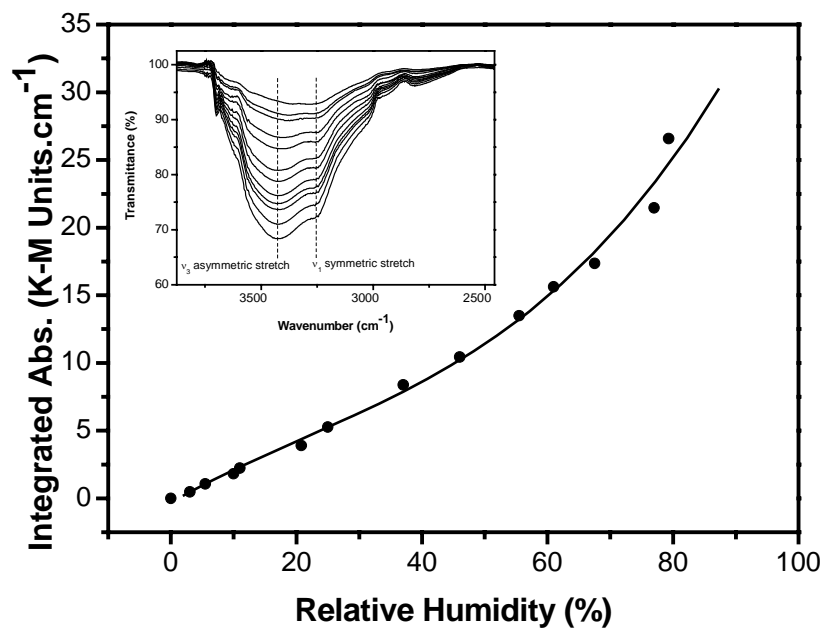

Fig. 1. Water uptake isotherm for calcite obtained using DRIFTS. Region integrated in shown in the inset.

The reflected radiation in DRIFTS is dependent on many factors including: particle dimension, packing density and homogeneity among others (Armaroli et al., 2004). In addition, unlike transmission FTIR, DRIFTS shows no linear relation between band intensity and concentration. Gaining quantitative information from the spectra is non-trivial as the Beer-Lambert law used in transmittance is not applicable. However, Kubelka-Munk theory can be applied to improve the linearity of the dependence of signal intensity upon concentration (Armaroli et al., 2004). By considering the reflection and absorbance of incident flux on a particle this methodology leads to expressions for these two parameters; in the limit of thick samples, it leads to a linear relationship between concentration and reflected radiation intensity.

Figure 1 shows the water adsorption isotherm obtained after applying the Kubelka-Munk function to the DRIFTS data. The isotherm exhibits type III characteristics indicative of a low adsorption enthalpy in the contact layer: the absence of a clear indication of the monolayer point makes coverage quantification problematic. Accordingly, in order to obtain absolute values of surface coverage thermogravimetric analysis (TGA) was used to measure the mass of adsorbed water as a function of relative humidity (Fig. 2, closed circles). Knowing the surface area of the sample $\left(17.8 \mathrm{~m}^{2} \mathrm{~g}^{-1}\right.$ from BET) the mass of water adsorbed was converted into coverage in terms of formal water monolayers by making a reasonable assumption about the size of the adsorbed water molecule (14.3 $\AA^{2}$ (Hackerman and Hall, 1958)). On this basis, we calculate that one monolayer is absorbed at $\sim 55 \%$ $R H$, adsorption proceeding up to $\sim 4.5$ monolayers at $80 \%$ $R H$. The shape of the corresponding isotherm (Fig. 2) resembles that of the DRIFTS-derived isotherm (Fig. 1) and Fig. 3 shows the correlation between TGA and DRIFTS results. This is linear at sub-monolayer coverage, but at higher

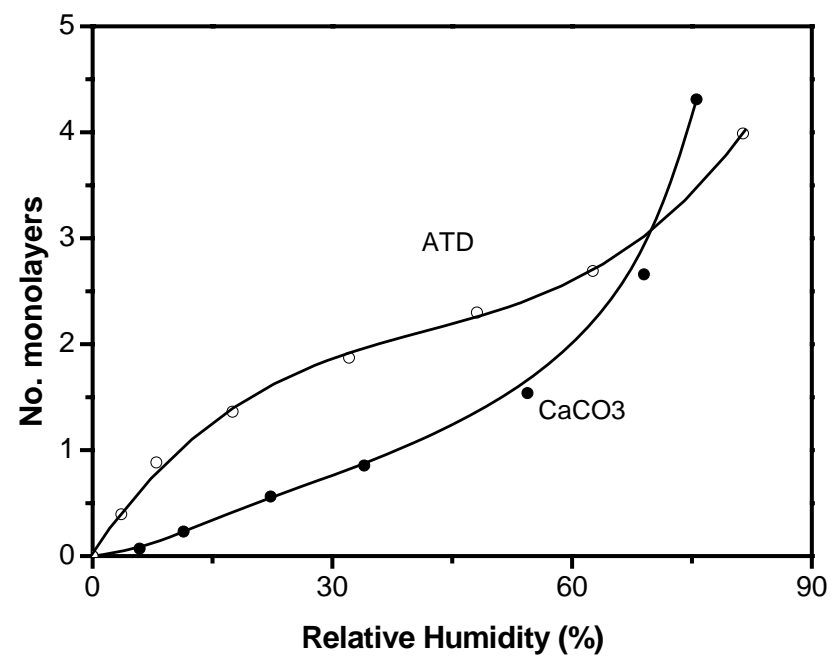

Fig. 2. Water uptake isotherms for calcite and ATD obtained using TGA.

coverages DRIFTS appears to underestimate the amount of adsorbed water.

\subsection{Hygroscopic growth of calcium carbonate aerosol}

The calcite aerosol was found to have a bimodal size distribution, which could be represented as the sum of two lognormal distributions of the form:

$$
\frac{d N}{d \ln D}=\frac{N}{\sqrt{2 \pi} \ln \sigma_{g}} \exp \left(-\frac{(\ln D-\ln D p g)^{2}}{2 \ln ^{2} \sigma_{g}}\right.
$$

where $\mathrm{D}$ is the particle diameter, $\mathrm{D}_{p g}$ the median diameter of the distribution and $\sigma_{g}$ the geometric standard deviation. At $5 \% R H$, values of $\mathrm{D}_{p g}$ of $40 \mathrm{~nm}$ and $\sigma_{g}$ of 1.5 were obtained for smaller of the two modes, while for the larger mode, $\mathrm{D}_{p g}=250 \mathrm{~nm}$ and $\sigma_{g}=1.4$.

The median diameter of the smaller mode was found to increase with increasing $R H$. Figure 4 shows the growth, plotted as $\mathrm{D}_{p g}(R H) / \mathrm{D}_{p g, 0}$ where $\mathrm{D}_{p g, 0}$ is the average "dry" median diameter, derived from measurements over the range 0 $30 \% R H$. At $80 \% R H$, a growth factor of $1.14 \pm 0.06$ is measured. The solid line shows a fit a power law expression of the form

$$
\frac{D}{D_{0}}=\left(1-\frac{R H}{100}\right)^{-\gamma}
$$

to the data, weighted by the uncertainty of each measurement. For $\mathrm{CaCO}_{3}, \gamma=0.073$. The measured size distribution at $50 \% R H$ is also shown as an inset to Fig. 4 .

\subsection{Water uptake on Arizona test dust}

The experiments were repeated on Arizona Test Dust (ATD) under the same conditions as used for calcite. Note that the 


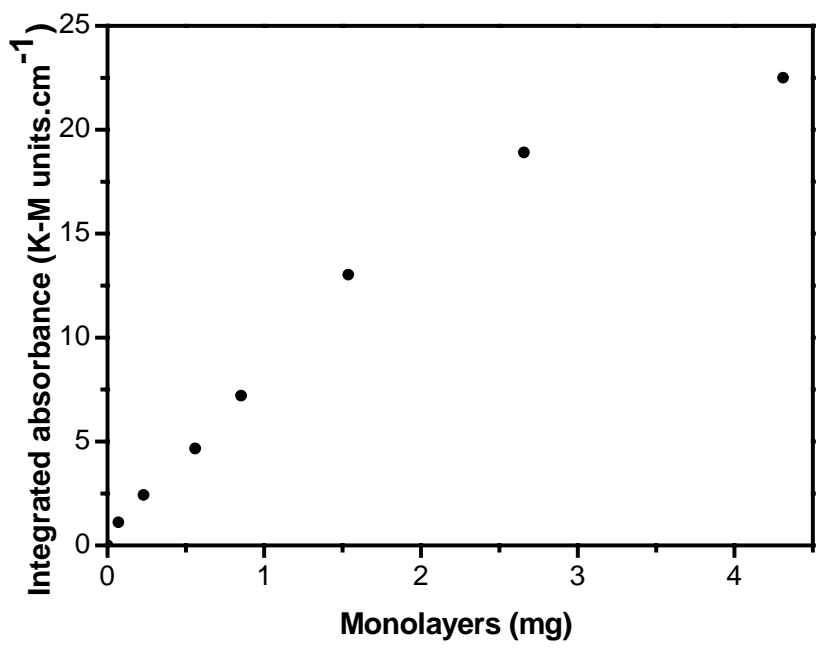

Fig. 3. Correlation between DRIFTS and TGA measurements for calcite.

TGA-derived isotherm (Fig. 2) is markedly different to that for $\mathrm{CaCO}_{3}$. In the present case a shoulder is clearly apparent indicating a higher enthalpy of adsorption into the contact layer. At sufficiently high $R H(\sim 70 \%)$ where multilayer formation is well developed ( $\sim 2.5$ layers) and the influence of the underlying solid surface reduced, the calcite and Arizona Test Dust isotherms converge, as would be expected. At $\sim 80 \% R H$ the coverage corresponds to $\sim 4$ monolayer for both samples. In the sub-monolayer range, the two isotherms are markedly divergent, reflecting the stronger water-Arizona Test Dust interaction in the contact layer, compared to water$\mathrm{CaCO}_{3}$. In passing, we note that the (physically reasonable) calculated coverages that characterize the monolayer and multilayer regimes of these isotherms validate our method of quantifying the TGA data. As in the case of $\mathrm{CaCO}_{3}$, the DRIFTS isotherm (Fig. 5) qualitatively resembles the TGA isotherm results but the two diverge at higher $R H$ to due nonlinearities in the spectral response.

\subsection{Hygroscopic growth of Arizona Test Dust aerosol}

As for the calcite particles, the aerosol generated from a suspension of Arizona Test Dust was found to be bimodal. At $5 \% \mathrm{RH}$, average values of $56 \mathrm{~nm}$ and $250 \mathrm{~nm}$ were obtained for $\mathrm{D}_{p g}$ in the two modes, with corresponding values of 1.4 for $\sigma_{g}$ for both modes. Figure 6 shows the hygroscopic growth factors of the small mode - slightly lower growth is observed, compared to the calcite particles. At $80 \% R H$, a growth factor of $1.07 \pm 0.02$ is observed. The solid line shows a fit of the power law expression, weighted by the uncertainty in each measurement, to the experimental data. For ATD, $\gamma=0.036$. The inset in Fig. 6 shows the measured size distribution at $50 \% R H$.

In view of the small amount of water soluble material present in commercial ATD samples, additional measure-

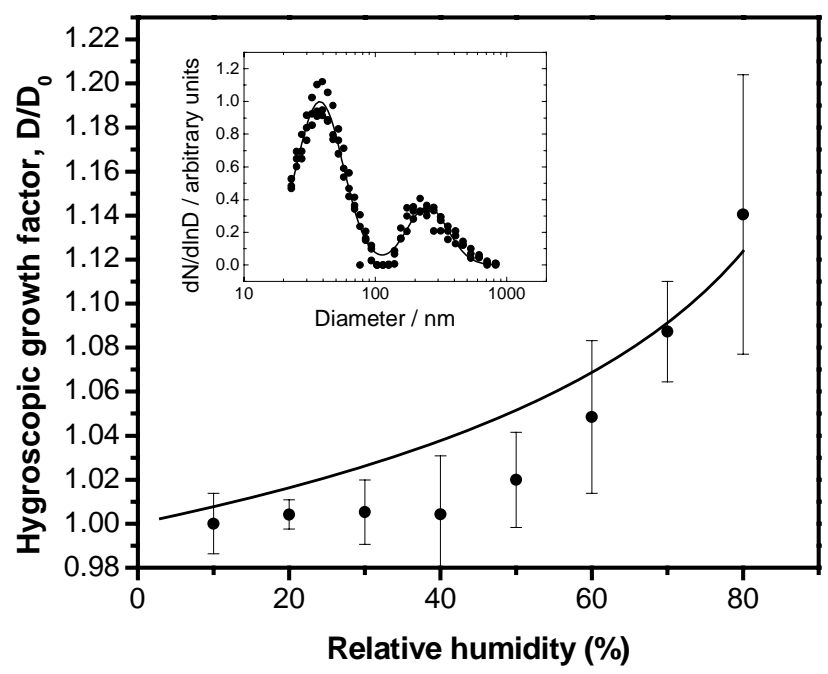

Fig. 4. Water uptake isotherm for $\mathrm{CaCO}_{3}$ obtained using DMA analysis.

ments were performed using samples from which the water soluble fraction had been removed by repeated treatment with deionized water. To within experimental error, identical growth factors were observed.

\section{Discussion}

The results described above represent the first comparative study of water uptake on mineral aerosols using three independent techniques: TGA, DRIFTS and DMA. Previous studies made use of Knudsen cell reactors (Seisel et al., 2004) to examine water uptake on mineral surfaces, the relative humidity range employed in such reactors being typically below $1 \%$. Given that most of the troposphere is characterized by moderate to high relative humidities, such experiments have an inherent limitation which can restrict their applicability for modeling. Other techniques have also been used to investigate water adsorption on mineral surfaces, including transmittance-FTIR (Al-Abadleh et al., 2003) and attenuated total reflectance spectroscopy (ATR-FTIR) (Al-Abadleh et al., 2005; Al-Hosney and Grassian, 2005). The underlying problem of the above-mentioned techniques is the lack of an absolute calibration making it highly desirable to verify reported results (Al-Abadleh et al., 2005, 2003) by independent techniques. Our measurements of water adsorption on $\mathrm{CaCO}_{3}$ by TGA (Fig. 3) show that monolayer coverage occurs at about $50 \%$ relative humidity, in good agreement with ATR-FTIR data (Al-Hosney and Grassian, 2005). TGA allowed the absolute and reliable isotherm to be defined over a large relative humidity range whereas that measured by Grassian et al. $(2003,2005)$ allowed only the identification of monolayer coverage. 


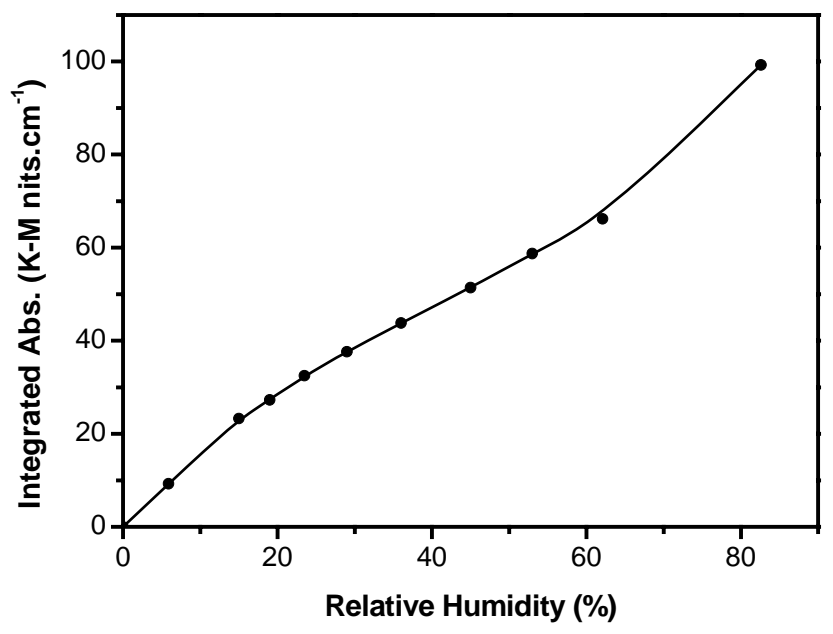

Fig. 5. Water uptake isotherm for ATD obtained using DRIFTS.

Arizona test dust consists principally of silica $(\sim 70 \%)$ and alumina $(\sim 20 \%)$ with small amounts of other minerals (oxides of iron, titanium, calcium etc.). In accord with this, our results for Arizona Test Dust do not differ significantly from published results for water uptake on silica and alumina powders (Goodman et al., 2001).

In order to rationalize the weaker interaction of water with $\mathrm{CaCO}_{3}$ compared to Arizona Test Dust at low relative humidity, it is necessary to consider the chemical interactions that occur at the solid/liquid interface. The interaction of silica (which dominates in Arizona Test Dust) with water is well understood (Papirer, 2000). It is thought that $\sim 3$ layers of water interact strongly with the surface via hydrogenbonding interactions involving the surface-capping silanol groups (Saliba et al., 2001). Higher layers behave essentially as liquid water.

The mechanisms of water interaction with calcite surfaces have been studied by several groups (Al-Hosney and Grassian, 2005; Stipp, 1999; Stipp et al., 1994). $\mathrm{CaCO}_{3}$ surfaces exposed to water vapour form $\mathrm{CO}_{3} \mathrm{H}^{-}$and $\mathrm{OH}^{-}$surface groups (Stipp, 1999), the resulting $\mathrm{Ca}(\mathrm{OH})\left(\mathrm{CO}_{3} \mathrm{H}\right)$ giving rise to enhanced hydrophilic properties and facilitating further water adsorption. It is suggested that at $<50 \% R H$ water forms 2-D islands with 3-D islands appearing at higher humidity (Al-Hosney and Grassian, 2005).

The isotherms obtained by TGA (Fig. 2) were used to calculate enthalpies of adsorption. The values obtained (from their corresponding BET parameters) were $45.7 \mathrm{kJmol}^{-1}$ for calcite and $52.2 \mathrm{kJmol}^{-1}$ in the case of Arizona Test Dust. The difference in adsorption enthalpies and the consequent difference in isotherms observed for these two samples (Fig. 2) reflects the different interaction strengths of the two types of surface hydroxylated groups with adsorbed water. One of several possible factors influencing interaction strength is the higher electronegativity of $\mathrm{Si}$ compared to $\mathrm{Ca}$ increases the polarity of the $-\mathrm{OH}$ group which in turn gives

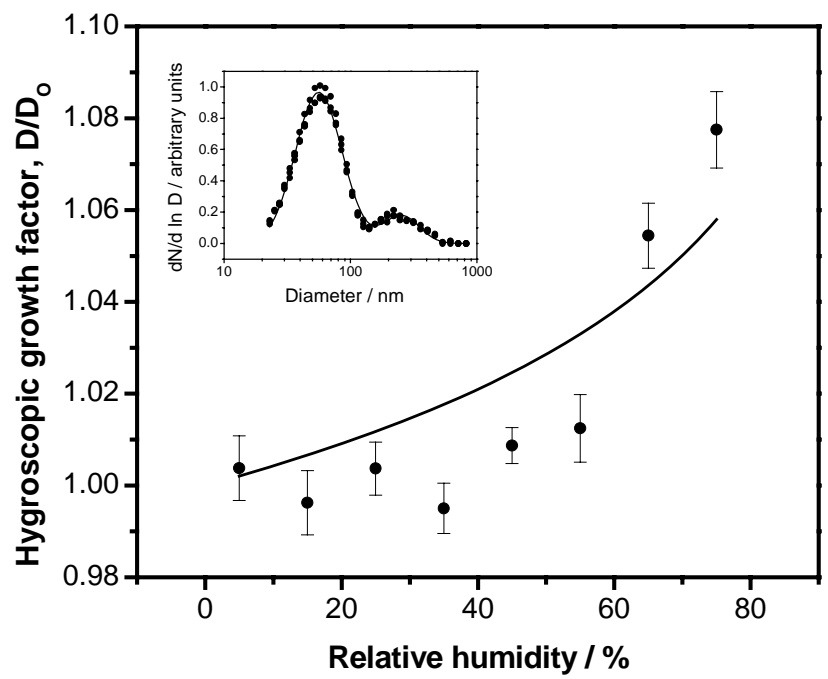

Fig. 6. Hygroscopic growth factors for ATD obtained using DMA analysis, measured for the small mode. The line is fit to a power-law expression (see text)

rise to stronger H-bonding in Arizona Test Dust. Thus the substantial differences in the early stages of water uptake between carbonate and Arizona Test Dust samples reflect the difference in chemical composition of two solids.

\subsection{DMA results}

A number of new observations concerning the hygroscopic properties of mineral dust surfaces are presented. Firstly, a bimodal size distribution has been observed for an aerosol generated from a suspension of solid particles in water. Secondly, hygroscopic growth factors have been measured and shown to increase monotonically with increasing $R H$ over the range $0-80 \%$, with similar growth factors $(\sim 1.10)$ being measured for both Arizona Test Dust and $\mathrm{CaCO}_{3}$ aerosol at $80 \% R H$.

The origin of the two modes observed in the size distribution is at this point not entirely clear. At the present time, we consider that the small mode is generated from nebulization of individual mineral dust particles in solution, while the larger mode is the result of agglomeration of particles within the liquid suspension.

A study was made of the effect of mass loading of the suspension on the particle size distribution function was performed but the results were inconclusive. We began with a very dilute suspension of ATD in water of around $30 \mathrm{mg}$ per liter, at which point only a single, small mode was observed. The concentration of the suspension was increased stepwise to $100 \mathrm{mg}$ per liter, at which point the second, larger mode was observed, and further to $300 \mathrm{mg}$ per liter. Over the range of concentrations studied, the gas phase number density of the large mode scaled linearly with that of the smaller. Thus, 


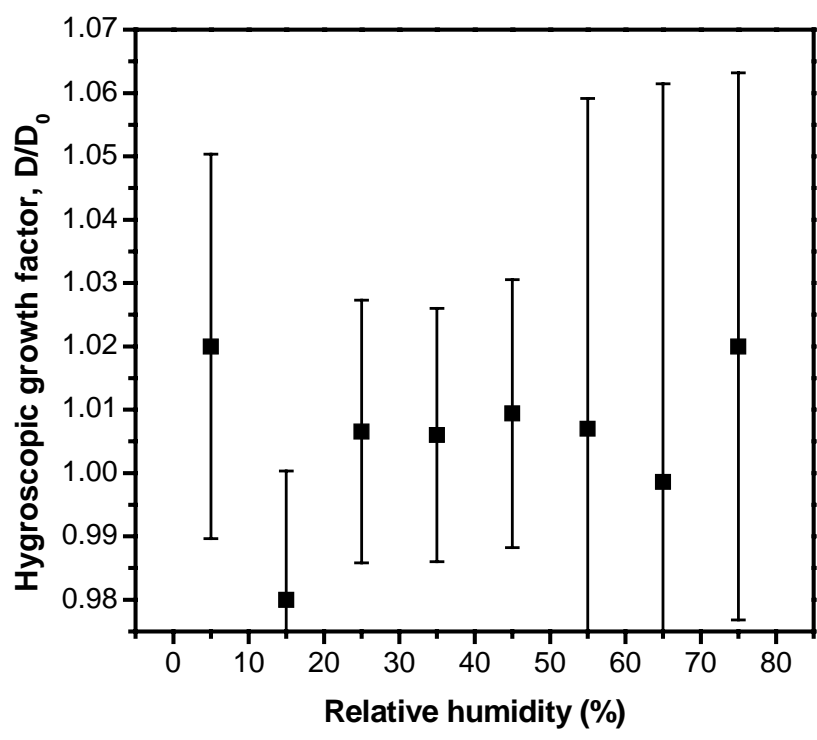

Fig. 7. Hygroscopic growth factors for ATD obtained using DMA analysis, measured for the large mode.

second order effects such as gas phase nucleation, may be excluded.

Figure 7 shows the hygroscopic growth of the large mode. To within the precision of our experiments, no hygroscopic growth was observed. Although perhaps surprising at first sight, these results are consistent with the hygroscopic growth factors of the smaller mode.

For a solid aerosol particle that is unable to absorb water into the bulk, the use of hygroscopic growth factors is somewhat misleading because condensation is then a purely surface phenomenon, and the observed growth factors are perhaps better expressed as the corresponding changes in particle diameter.

For example, in the case of ATD, hygroscopic growth factors of 1.09 were derived for the small mode at $80 \%$, corresponding to a change in diameter of around $3 \mathrm{~nm}$. This lies well within the precision of the DMA measurement technique. At $250 \mathrm{~nm}$ no growth can be observed as the predicted increase in diameter is within the uncertainty of the measurement. Thus, the data shown in Fig. 7, while noisy and showing no clear trend in growth with increasing $R H$, do not contradict our measurements of growth of the small mode. They are simply more precise measurements of the same growth process.

Conversion of changes in (mobility derived) particle diameter to surface coverage is not straightforward, being complicated by uncertainties arising from changes in particle shape (which affects mobility) and of the molecular diameter of water on the surface, an estimate of surface coverage may be made using the growth measurements. Taking the area of an adsorbed water molecule as $14.3 \AA^{2}$ (Hackerman and Hall, 1958 ) and assuming a flat adsorption geometry, a molecular diameter of $420 \mathrm{pm}$ is derived. Thus a change in particle diameter of $5 \mathrm{~nm}$, as measured for calcium carbonate, is equivalent to a coverage of $6 \mathrm{ML}$. For ATD, coverages of around $4 \mathrm{ML}$ are calculated. Both results agree with the TGA and DRIFTS data within the experimental uncertainties.

To date, there have been only a few atmospheric observations relating to the hygroscopic growth of mineral dust aerosol. Carrico et al. report hygroscopic growth factors derived from measurements of the radiative properties of aerosol during the ACE-ASIA campaign (Carrico et al., 2003). The ratios of total light scattering coefficients at $550 \mathrm{~nm}$ were used to derive hygroscopic growth factors, which during dust-dominated events, were found to be in the range 1.18 to 1.39 , although there are indications that this value contains a contribution from an electrolyte component. Li-Jones et al. (1998) measured hygroscopic growth factors for mineral dust particles advected over the Atlantic Ocean. Aerosol scattering coefficients were measured using an integrating nephelometer and growth factors of 1.0 to 1.1 were estimated using data from periods of high dust concentration. In view of these studies, and the results reported in this work, a diameter-dependent growth factor is recommended for mineral dust aerosol. For freshly emitted $100 \mathrm{~nm}$ mineral dust particles in the atmosphere a growth factor of 1.05 is suggested, falling to 1.005 , or $0.5 \%$, for $1 \mu \mathrm{m}$ particles.

\section{Conclusions}

1. Arizona Test Dust and $\mathrm{CaCO}_{3}$ show markedly different water uptake characteristics over the $R H$ range 0 $80 \%$. These differences in behaviour are understandable in terms of differences in specific interactions at the solid/liquid interface.

2. TGA provides a reliable quantitative measure of water uptake over the entire $R H$ range enabling relatively unambiguous identification of the monolayer point. DRIFT spectra scale linearly with TGA data at low $R H$, but diverge significantly at high $R H$.

3. Our laboratory measurements of hygroscopic growth factors are in accord with both field measurements and with our spectroscopic and gravimetric results. The results indicate moderate hygroscopicity of the mineral dusts, and provide important new data of relevance for the calculation of the rate of uptake of soluble gases by mineral aerosol and the radiative properties of these particles.

Acknowledgements. This work was supported under Research Grant NE/B503509/1 awarded by the Natural Environment Research Council (NERC). R. J. Gustafsson thanks NERC for the award of a research studentship and P. T. Griffiths thanks the NERC Distributed Institute for Atmospheric Composition for a post-doctoral fellowship. 
Edited by: J. Abbatt

\section{References}

Al-Abadleh, H. A., Al-Hosney, H. A., and Grassian, V. H.: Oxide and carbonate surfaces as environmental interfaces: the importance of water in surface composition and surface reactivity, J. Molecular Catalysis a-Chemical, 228, 47-54, 2005.

Al-Abadleh, H. A., Krueger, B. J., Ross, J. L., and Grassian, V. H.: Phase transitions in calcium nitrate thin films, Chemical Communications, 2796-2797, 2003.

Al-Hosney, H. A. and Grassian, V. H.: Water, sulfur dioxide and nitric acid adsorption on calcium carbonate: A transmission and ATR-FTIR study, Phys. Chem. Chem. Phys., 7, 1266-1276, 2005.

Armaroli, T., Becue, T., and Gautier, S.: Diffuse reflection infrared spectroscopy (DRIFTS): Application to the in situ analysis of catalysts, Oil \& Gas Science and Technology-Revue De L Institut Francais Du Petrole, 59, 215-237, 2004.

Carrico, C. M., Kus, P., Rood, M. J., Quinn, P. K., and Bates, T. S.: Mixtures of pollution, dust, sea salt, and volcanic aerosol during ACE-Asia: Radiative properties as a function of relative humidity, J. Geophys. Res.-Atmospheres, 108, 8650-8668, 2003.

Charlson, R. J., Schwartz, S. E., Hales, J. M., Cess, R. D., Coakley, J. A., Hansen, J. E., and Hofmann, D. J.: Climate Forcing by Anthropogenic Aerosols, Science, 255, 423-430, 1992.

Dentener, F. J., Carmichael, G. R., Zhang, Y., Lelieveld, J., and Crutzen, P. J.: Role of mineral aerosol as a reactive surface in the global troposphere, J. Geophys. Res.-Atmospheres, 101, 22869 $22889,1996$.

Garrett, T. J., Russell, L. M., Ramaswamy, V., Maria, S. F., and Huebert, B. J.: Microphysical and radiative evolution of aerosol plumes over the tropical North Atlantic Ocean, J. Geophys. Res.Atmospheres, 108, 4022-4038, 2003.

Goodman, A. L., Bernard, E. T., and Grassian, V. H.: Spectroscopic study of nitric acid and water adsorption on oxide particles: Enhanced nitric acid uptake kinetics in the presence of adsorbed water, J. Phys. Chem. A, 105, 6443-6457, 2001.

Hackerman, N. and Hall, A. C.: The adsorption of water vapor on quartz and caclite, J. Phys. Chem., 62, 1212-1214, 1958.

Hallquist, M., Stewart, D. J., Stephenson, S. K., and Cox, R. A.: Hydrolysis of $\mathrm{N}_{2} \mathrm{O}_{5}$ on sub-micron sulfate aerosols, Phys. Chem. Chem. Phys., 5, 3453-3463, 2003.
Hanke, M., Umann, B., Uecker, J., Arnold, F., and Bunz, H.: Atmospheric measurements of gas-phase $\mathrm{HNO}_{3}$ and $\mathrm{SO}_{2}$ using chemical ionization mass spectrometry during the MINATROC field campaign 2000 on Monte Cimone, Atmos. Chem. Phys., 3, 417 436, 2003,

SRef-ID: 1680-7324/acp/2003-3-417.

Kaufman, Y. J., Tanre, D., and Boucher, O.: A satellite view of aerosols in the climate system, Nature, 419, 215-223,2002.

Li-Jones, X. and Prospero, J. M.: Variations in the size distribution of non-sea-salt sulfate aerosol in the marine boundary layer at Barbados: Impact of African dust, J. Geophys. Res.Atmospheres, 103, 16073-16 084, 1998.

Lindqvist, O., Ljungstrom, E., and Svensson, R.: Low-Temperature Thermal-Oxidation of Nitric-Oxide in Polluted Air, Atmos. Environ., 16, 1957-1972, 1982.

Loyepilot, M. D., Martin, J. M., and Morelli, J.: Influence of Saharan Dust on the Rain Acidity and Atmospheric Input to the Mediterranean, Nature, 321, 427-428, 1986.

Papirer, E.: Adsorption on Silica Surfaces, Marcel Dekker, New York, 2000.

Ravishankara, A. R. and Longfellow, C. A.: Reactions on tropospheric condensed matter, Phys. Chem. Chem. Phys., 1, 54335441, 1999.

Saliba, N. A., Yang, H., and Finlayson-Pitts, B. J.: Reaction of gaseous nitric oxide with nitric acid on silica surfaces in the presence of water at room temperature, J. Phys. Chem. A, 105, 10339-10346, 2001.

Savoie, D. L. and Prospero, J. M.: Particle-Size Distribution of Nitrate and Sulfate in the Marine Atmosphere, Geophys. Res. Lett., 9, 1207-1210, 1982.

Seisel, S., Lian, Y., Keil, T., Trukhin, M. E., and Zellner, R.: Kinetics of the interaction of water vapour with mineral dust and soot surfaces at T=298 K, Phys. Chem. Chem. Phys., 6, 1926-1932, 2004.

Stipp, S. L. S.: Toward a conceptual model of the calcite surface: Hydration, hydrolysis, and surface potential, Geochim. Cosmochim. Acta, 63, 3121-3131, 1999.

Stipp, S. L. S., Eggleston, C. M., and Nielsen, B. S.: Calcite Surface-Structure Observed at Microtopographic and Molecular Scales with Atomic-Force Microscopy (AFM), Geochim. Cosmochim. Acta, 58, 3023-3033, 1994.

Tegen, I. and Fung, I.: Modeling of Mineral Dust in the Atmosphere - Sources, Transport, and Optical-Thickness, J. Geophys. Res.Atmospheres, 99, 22 897-22 914,1994. 